\title{
Experimental Study of Curved Guide Tubes for Pellet Injection*
}

\author{
S. K. Combs, L. R. Baylor, C. R. Foust, M. J. Gouge, T. C. Jernigan, and S. L. Milora \\ Oak Ridge National Laboratory \\ Post Office Box 2009, Oak Ridge, TN 37831-8071
}

\begin{abstract}
The use of curved guide tubes for transporting frozen hydrogen pellets offers great flexibility for pellet injection into plasma devices. While this technique has been previously employed, an increased interest in its applicability has been generated with the recent ASDEX Upgrade experimental data for magnetic high-field side (HFS) pellet injection. In these innovative experiments, the pellet penetration appeared to be significantly deeper than for the standard magnetic low-field side injection scheme, along with corresponding greater fueling efficiencies. Thus, some of the major experimental fusion devices are planning experiments with HFS pellet injection. Because of the complex geometries of experimental fusion devices, installations with multiple curved guide tube sections will be required for HFS pellet injection. To more thoroughly understand and document the capability of curved guide tubes, an experimental study is under way at the Oak Ridge National Laboratory (ORNL). In particular, configurations and pellet parameters applicable for the DIII-D tokamak and the International Thermonuclear Experimental Reactor (ITER) were simulated in laboratory experiments. Initial test results with nominal $2.7-$ and $10-\mathrm{mm}$-diam deuterium pellets are presented and discussed.
\end{abstract}

\section{INTRODUCTION}

The process and benefits of plasma fueling by the injection of frozen pellets of hydrogen isotopes into magnetically confined plasmas have been thoroughly documented in the literature (for example, [1] and [2]). The pellet fabrication/acceleration hardware is usually located some distance from the fusion vacuum chamber ( $\sim 10 \mathrm{~m}$ or more for some installations). Straight guide tubes have typically been used to transport and deliver pellets from the output of the accelerator to the plasma, avoiding the detrimental effects on pellet size and velocity associated with curved guide tubes. A slight curvature of the guide tubes may be beneficial on fusion reactor devices because it limits the line-of-sight radiation and subsequent activation of injector components. However, curved guide tubes with smaller radii are required for magnetic high-field side (HFS) injection as recently reported on ASDEX Upgrade [3]. With the use of curved guide tubes, the speed at which intact pellets can be delivered will be somewhat limited, with some additional losses in both pellet velocity and mass as compared to the straight guide tube reference. Büchl and Sandmann [4] presented a paper on guide tubes in 1982, including some experimental results with nominal 0.6-, 1.5-, and 2.6-mm-diam pellets and curved guide tubes. They also proposed a simple model for evaluating the speed limit without pellet fracturing; the model assumes that the centrifugal forces produce stresses in the pellet and that fracturing occurs whenever the magnitude of the stress exceeds a limiting value as determined by the strength of the deuterium ice. Thus, the model predicts a maximum speed that pellets can survive for any given radius of curvature. The minimum radius of curvature $\left(r_{\min }\right)$ that the pellet can withstand can be expressed as a function of the pellet velocity (v) and mass (m):

$$
r_{\min }=m \cdot v^{2} \sigma \cdot A
$$

with the ultimate tensile stress $(\sigma)$ information taken from the literature for deuterium ice [5] and the effective pellet contact area with the guide tube (A) taken as half of the cylindrical pellet surface. The tensile strength of deuterium ice ranges from $\sim 5$ bar at $6 \mathrm{~K}$ to $\sim 3$ bar at $15 \mathrm{~K}$; previous Oak Ridge National Laboratory (ORNL) pipe gun data indicated that the shear strength was similar to the tensile strength (4 bar was used for all model calculations).

In this paper, the initial results from an experimental study of curved guides tubes are reported and compared to the simple model.

\section{EXPERIMENTAL EQUIPMENT}

Two pneumatic pellet injector facilities were used for this study: (a) a repeating pneumatic injector (RPI) and (b) a pipe gun injector. The prototype RPI $[6,7]$ was fitted with components to test curved guide tubes. With this type injector, deuterium ice is provided to the acceleration section by a cryogenic extruder, and pellets are punched and accelerated in the gun assembly. For this study, the injector was equipped with a punch/barrel combination with a $2.7-\mathrm{mm}$ bore. This pellet size is relevant for most present large tokamak experiments such as DIII-D, which is equipped with two RPIs of that size. A new pipe gun injector was fabricated specifically for this study. The, pipe gun is a technique in which a single deuterium pellet is frozen in situ in the gun barrel $[8,9]$. For the initial experiments, it was equipped with a nominal $10-\mathrm{mm}$-diam barrel; this pellet size is more 
applicable for the International Thermonuclear Experimental Reactor (ITER) [10]. Different pellet speeds were obtained in the experiments by adjusting the gas supply pressure and the total gas flow through the ORNL propellant valve [11]. Helium and hydrogen gases at supply pressures of $\sim 5$ to 70 bar were used for propellants. The basic experimental configurations are shown in Fig. 1 and included single curved guide tube sections of $90^{\circ}$. The material used for the guide tubes was standard commercial stainless steel, and no special surface finish was specified. Test tubes were cleaned to remove general dirt and grease. For the $2.7-\mathrm{mm}$ tests, the inside diameter of the guide tubes was $\sim 8.1$ to $8.5 \mathrm{~mm}$; for the $10-\mathrm{mm}$ tests, the inside diameter of the guide tubes was -23 $\mathrm{mm}$. A test with multiple curved sections (three sections of $90^{\circ}$ each) was also carried out and is described in the next section.

\section{TEST RESULTS}

\section{A. 2.7-mm-diam Pellets}

Tests were carried out with four guide tubes of different curvature (5-, 20-, 40-, and 92-cm radius ). Fig. 2 shows a typical data set and includes the scope traces (three light gates and a target plate shock accelerometer) and pellet photographs at the entrance and exit of the curved guide tube. The scope data are used to determine pellet velocities, and the photographs provide information on pellet size and integrity. As shown in Fig. 2, the pellet at $250 \mathrm{~m} / \mathrm{s}$ survived the $20-\mathrm{cm}$ radius curved guide tube. The data can also be used to estimate velocity and mass losses in the curved guide tubes. For this paper, only pellet data relative to pellet integrity will be presented and discussed.

In Fig. 3, exit photographs for two test shots at $440 \mathrm{~m} / \mathrm{s}(40-$ $\mathrm{cm}$-radius curved guide tube) are shown; one pellet is observed to be intact, and one is fractured. This was observed quite often during the experiments. A review of the data suggested that a transition region was the best way to present the data. In Fig. 4, the radius of curvature is plotted as a function of pellet velocity, and a transition region is shown for each radius of curvature. At pellet velocities below the region, pellets were always found to be intact; at velocities above the region, pellets were always found to be fractured. In the transition region, both intact and fractured pellets were observed. Hundreds of pellets were fired in the experiments, and most were carried out in or near the transition regions. Calculations from the simple model are shown in Fig. 4 for comparison and provide a relatively smooth curve. For good agreement with the model, the transition regions should fall near the curve for each radius of curvature. However, the experimental data and the model were in reasonable agreement for only the 5- and $20-\mathrm{cm}$-radius data sets. The data indicate a velocity limit of 400 to $500 \mathrm{~m} / \mathrm{s}$ for even the relatively large 92 -cm-radius tests, whereas the model suggests that intact pellets could be expected at velocities in excess of $1000 \mathrm{~m} / \mathrm{s}$ for the larger radius of curvature. Another interesting observation is that the pellet velocity was more limited for the $40-\mathrm{cm}$-radius tube than the 20 -cm-radius tube.

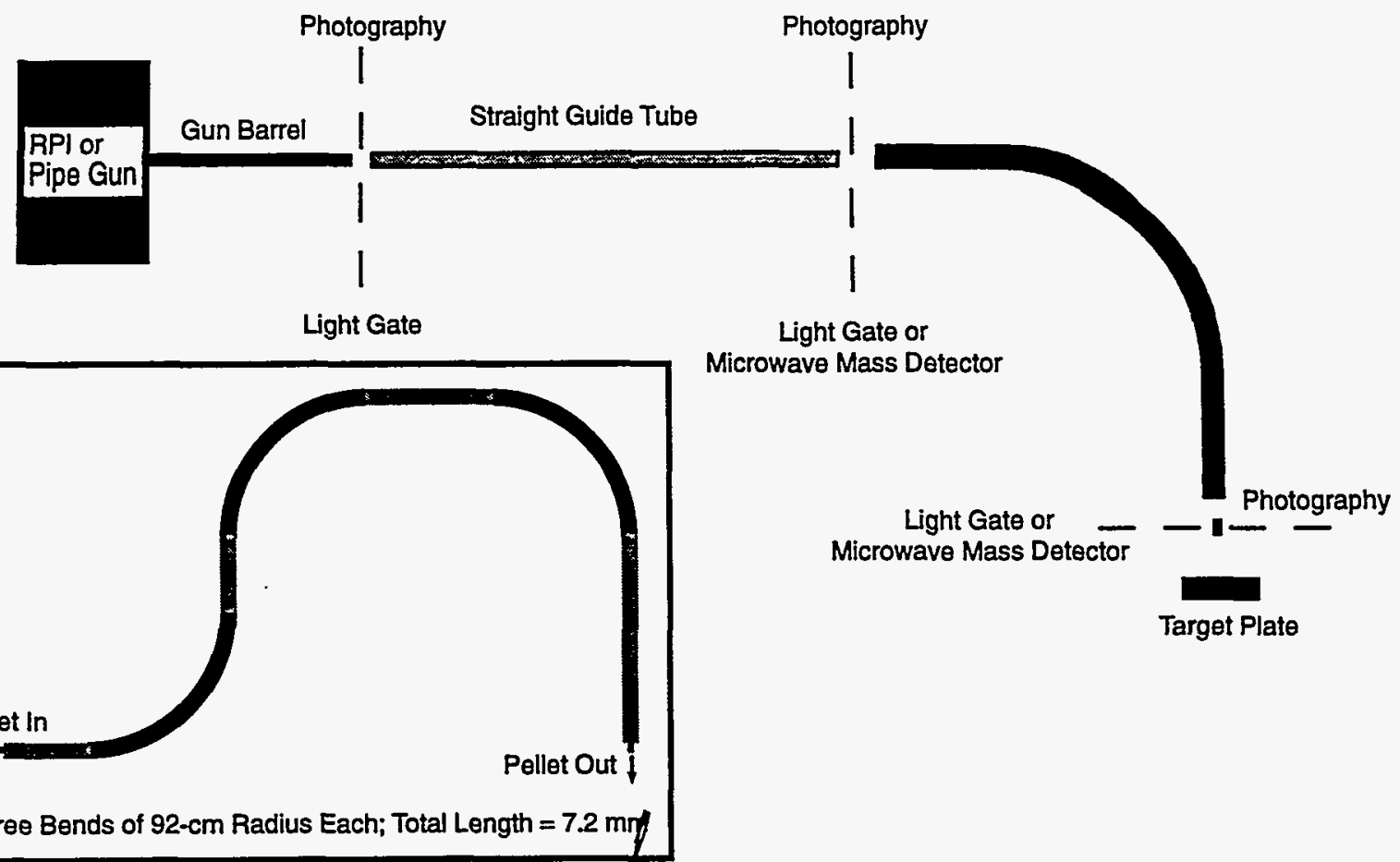

Fig. 1. Test configurations for experimental study of curved guide tubes (inset shows special setup with multiple bends). 


\section{DISCLAIMER}

This report was prepared as an account of work sponsored by an agency of the United States Government. Neither the United States Government nor any agency thereof, nor any of their employees, makes any warranty, express or implied, or assumes any legal liability or responsibility for the accuracy, completeness, or usefulness of any information, apparatus, product, or process disclosed, or represents that its use would not infringe privately owned rights. Reference herein to any specific commercial product, process, or service by trade name, trademark, manufacturer, or otherwise does not necessarily constitute or imply its endorsement, recommendation, or favoring by the United States Government or any agency thereof. The views and opinions of authors expressed herein do not necessarily state or reflect those of the United States Government or any agency thereof. 


\section{DISCLAMIER}

Portions of this doecoment may be illegible in electronic image produets. Ingages are produced from the best available original doceoment. 
Data traces

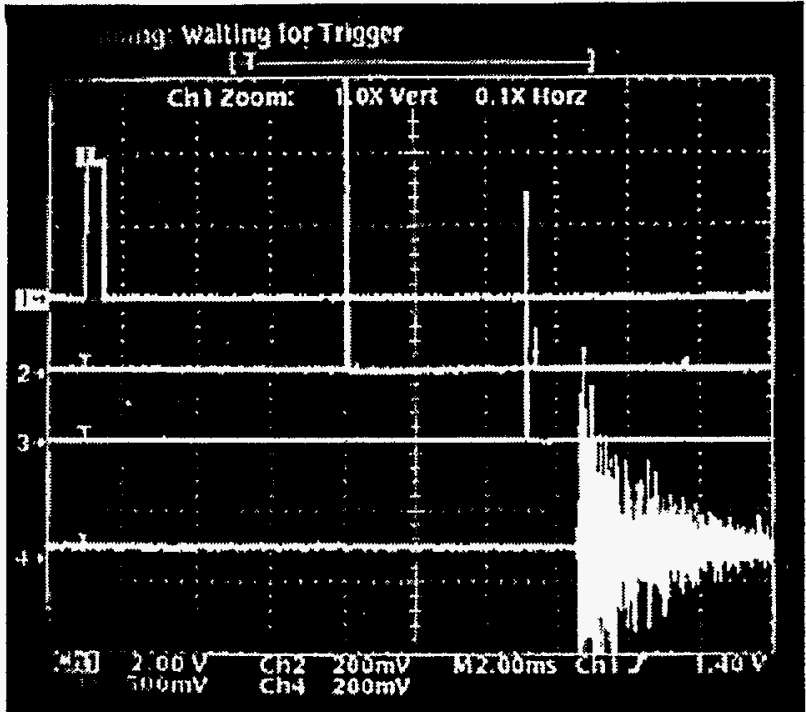

Three light gates and a target plate provide timing information for evaluating pellet speeds

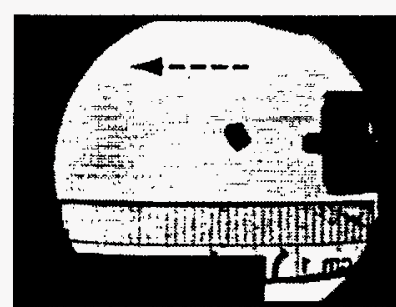

Photograph before entering curved section

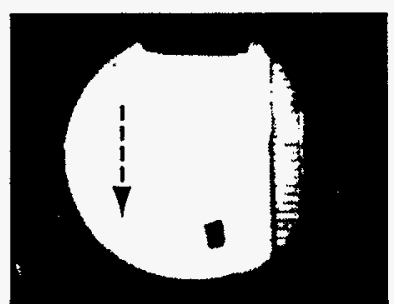

Photograph after exiting curved section
Fig. 2. Data set for $2.7-\mathrm{mm}$ pellet shot at $250 \mathrm{~m} / \mathrm{s}$ through a $20-\mathrm{cm}-$ radius curved guide tube (scale in $\mathrm{mm} / \mathrm{div}$ ).

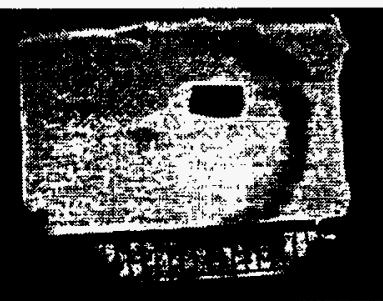

Intact Pellet

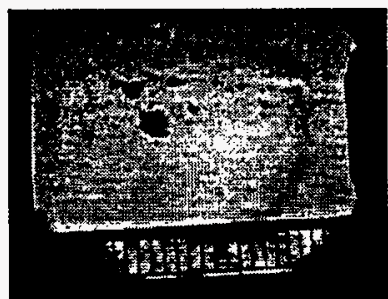

Fractured Pellet
Fig. 3. Photographs of $2.7-\mathrm{mm}$ pellets exiting $40-\mathrm{cm}$-radius curved guide tube; inlet velocity $=440 \mathrm{~m} / \mathrm{s}$ (scale in $\mathrm{mm} / \mathrm{div}$ ).

Tests with three sections of curved guide tubes (92-cm radius and $90^{\circ}$ each) as shown in Fig. 1 were carried out; in general, the data set agreed quite well with the experimental results for a single bend (Fig. 4).

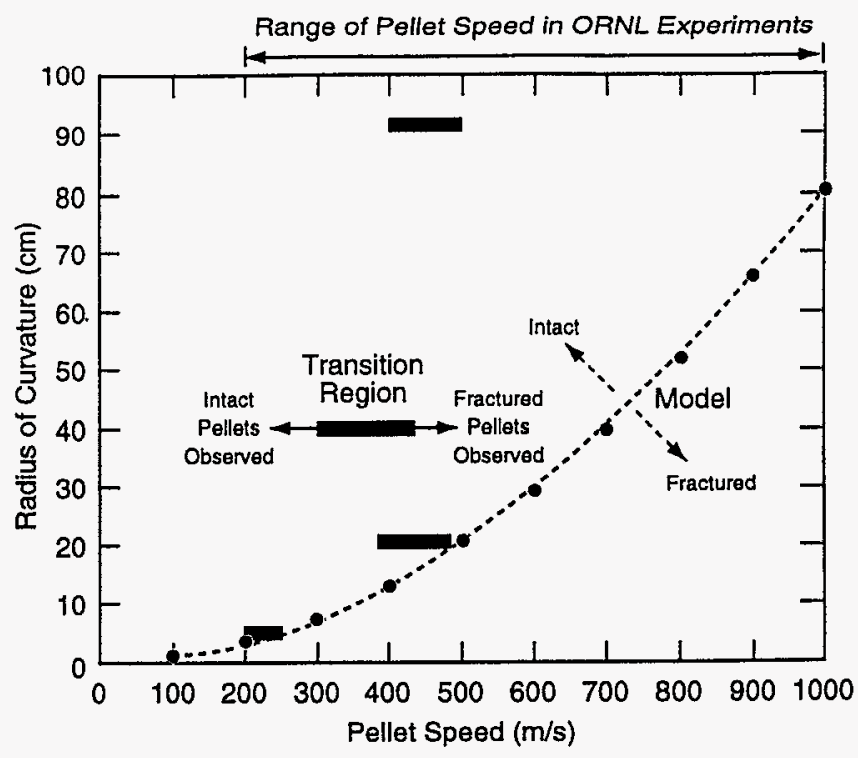

Fig. 4. Test data summary for $2.7-\mathrm{mm}$ pellets shot through curved guide tubes of different radii (a simple model based on centrifugal forces is shown).

\section{B. 10-mm-diam Pellets}

Tests with only one radius of curvature $(80 \mathrm{~cm})$ have been conducted with the larger pellet size, and this curvature was chosen because it is the tightest radius of curvature planned for the pellet line installation for HFS injection on ITER. It was found that the $10-\mathrm{mm}$ pellets were always fractured at velocities above $300 \mathrm{~m} / \mathrm{s}$ and were usually intact at $\leq 300 \mathrm{~m} / \mathrm{s}$. Some typical photograph sets are shown in Fig. 5. For this
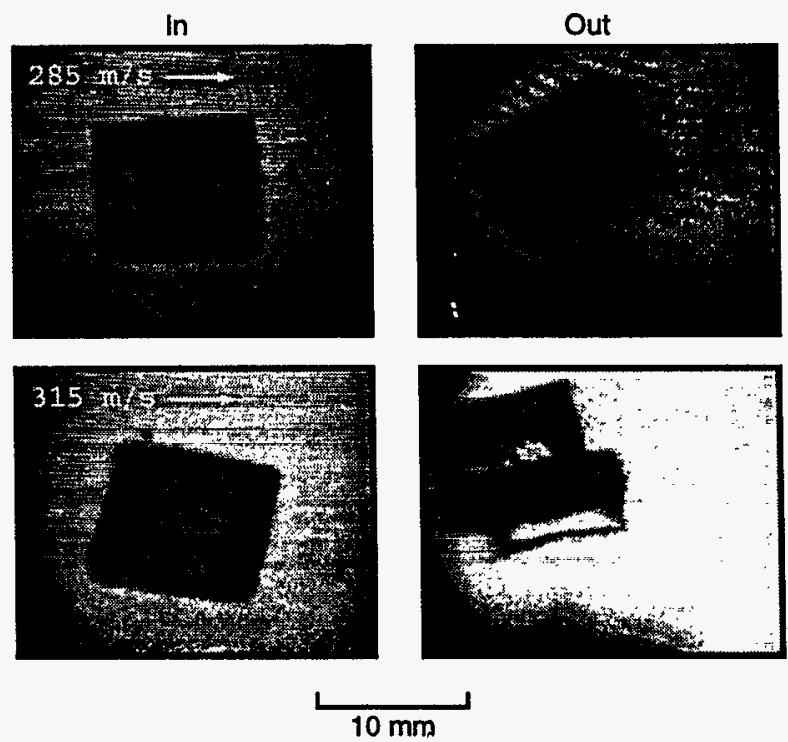

Fig. 5. Photograph sets for 10 -mm pellets shot through 80 -cm-radius curved guide tube. 
case, the transition region was much smaller $(-280$ to $300 \mathrm{~m} / \mathrm{s})$ than for the $2.7-\mathrm{mm}$ data sets. The model predicts a velocity limit of $-520 \mathrm{~m} / \mathrm{s}$ for this pellet size and configuration, which is 1.7 times the experimental limit.

\section{SUMMARY}

Based on the initial test results of this study, curved guide tubes can be used to reliably deliver intact pellets at velocities of several hundreds of meters per second or greater, depending on the pellet size and radius of curvature. More thorough analyses of the operating techniques and data are needed to evaluate possible systematic effects on the test results. However, based on the preliminary analyses, it appears that the simple model described in the introduction is not adequate to predict guide tube performance for the parameter range of this study. With the many parameters and factors that are significant in the pellet/surface interaction for this process, it is not surprising that a simple model based only on centrifugal forces would be inadequate. Thus, laboratory experimen $\}$ is the best technique to document the operating regime for reliable performance for any test configuration. With more experimental data, improved models can probably be developed.

\section{REFERENCES}

[1] S. L. Milora, W. A. Houlberg, L.L. Lengyel, and V. Mertens, "Pellet fueling," Nucl. Fusion 35, 657 (1995).

[2] S. K. Combs, "Pellet injection technology," Rev. Sci. Instrum. 67, 1679 (1993). (invited review paper)

[3] P. T. Lang, K. Büchl, M. Kaufmann, R. S. Lang, V. Mertensr, H. W. Müller, J. Neuhauser, ASDEX Upgrade Team, and NBI Team, "Pellet Injection into ASDEX Upgrade Plasmas with Improved Scenario from the Magnetic High-Field Side," Max-Planck Institut für Plasmaphysik Report IPP 1/304 (October 1996).

[4] K. Büchl and W. Sandmann, "Launching of D2-pellets through guide tubes," in Fusion Technology 1982, Proc. I2th Symposium, Julich, 13-17 September 1982, Vol. 2. Oxford: Pergamon Press, 1982, p. 1507.

[5] D. N. Bolshutkin, Y. E. Stetsenko, and L. A. Alekseeva, "Plastic deformation and stress relaxation in solid normal deuterium," Sov. Phys. Solid State 12, 119 (1970).

[6] S. K. Combs, S. L. Milora, C. R. Foust, C. A. Foster, and D. D. Schuresko, "Repeating pneumatic hydrogen pellet injector for plasma fueling," Rev. Sci. Instrum. 56, 1173 (1985).

[7] S. K. Combs, S. L. Milora, C. R. Foust, G. L. Schmidt, and T.P. McBride, "Operation of repeating pneumatic hydrogen pellet injector on TFTR," J. Vac. Sci. Technol. A4(3), 1113-1117 (May/June 1986).

[8] S. K. Combs, S. L. Milora, and C. R. Foust, "Simple pipe gun for hydrogen pellet injection," Rev. Sci. Instrum. 57, 2636 (1986).

[9] P. W. Fisher, S. L. Milora, S. K. Combs, R. V. Carison, and D. O. Coffin, "Tritium proof-of-principle injector experiment," Fusion Technology 14, 977 (1988).

[10] M. J. Gouge, K. D. St. Onge, S. L. Milora, P. W. Fisher, and S. K. Combs, "Pellet fueling system for ITER," Fusion Engineering and Design 19(1), 53 (1992).

[11]. S. L. Milora, S. K. Combs, and C. R. Foust, "Fast-opening magnetic valve for high-pressure gas injection and applications to hydrogen pellet fueling systems," Rev. Sci. Instrum. 57, 2356 (1986).

1

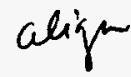

